\begin{abstract}
Iranica
Abstracta Iranica Revue bibliographique pour le domaine irano-aryen

Volume 34-35-36 | 2017

Comptes rendus des publications de 2011-2013
\end{abstract}

\title{
Florian S. Knauss, Iulon Gagosidse, Ilyas Babaev. Karačamirli: Ein persisches Paradies
}

\section{Astrid Nunn}

\section{(2) OpenEdition}

1 Journals

\section{Édition électronique}

URL : http://journals.openedition.org/abstractairanica/41693

DOI : 10.4000/abstractairanica.41693

ISSN : 1961-960X

Éditeur :

CNRS (UMR 7528 Mondes iraniens et indiens), Éditions de l'IFRI

Référence électronique

Astrid Nunn, «Florian S. Knauss, Iulon Gagosidse, Ilyas Babaev. Karačamirli: Ein persisches Paradies », Abstracta Iranica [En ligne], Volume 34-35-36 | 2017, document 89, mis en ligne le 15 juillet 2016, consulté le 27 septembre 2020. URL : http://journals.openedition.org/abstractairanica/41693 ; DOI : https://doi.org/10.4000/abstractairanica.41693

Ce document a été généré automatiquement le 27 septembre 2020.

Tous droits réservés 


\title{
Florian S. Knauss, Iulon Gagosidse, Ilyas Babaev. Karačamirli: Ein persisches Paradies
}

\author{
Astrid Nunn
}

\section{RÉFÉRENCE}

Florian S. Knauss, Iulon Gagosidse, Ilyas Babaev. « Karačamirli: Ein persisches Paradies ». ARTA 2013.004, 29 p. http://www.achemenet.com/pdf/arta/ARTA-2013.004-KnaussGagosidse-Babaev.pdf

1 Les fouilles de Karačamirli (Azerbaïdjan) ont révélé des propylées (Ideal Tepe) dont le plan et les bases campaniformes de colonnes correspondent au tripylon de Persépolis. Ces propylées menaient à un palais situé à $200 \mathrm{~m}$ de là sur le site nommé Gurban Tepe. $2000 \mathrm{~m}^{2}$ des 4000 que le palais devait couvrir ont été explorés par la mission allemande. Ce bâtiment construit en briques mesure $65,50 \mathrm{~m} \times 62,90 \mathrm{~m}$ et consiste en une salle hypostyle centrale entourée de salles également hypostyles mais plus petites. Les briques non cuites mesurent $33 \mathrm{~cm} \times 33 \mathrm{~cm} \times 12 \mathrm{~cm}$ et correspondent ainsi au standard achéménide. Environ 150 bases de colonnes furent retrouvées. Elles diffèrent selon les salles et celles campaniformes sont particulièrement belles. Les colonnes elles-mêmes étaient très vraisemblablement en bois; aucune trace de stuc ne subsiste. Comme pour Dahāneh-e Ǵolāmān le prototype de cette architecture est Persépolis. D'autres structures révélées par une prospection magnétique indiquent que Karačamirli fut vraisemblablement fondée au début du $\mathrm{V}^{\mathrm{e}} \mathrm{s}$., et que le Grand Roi y était représenté avec une administration, une garnison et ce qu'il fallait d'agriculture et de production pour les entretenir.

2 Cet article offre, outre un rapport sur Karačamirli, un résumé des vestiges d'époque achéménide au Caucase. Ils consistent en bases de colonnes carrées surmontées d'un gros tore ou campaniformes trouvées dans plusieurs sites en Arménie et en Géorgie, où 
le plus connu est Gumbati dont une partie du palais est encore préservée. Colonnes et palais ont également été retrouvés en Azerbaïdjan à Sari Tepe. Le site de Zichia-Gora en Géorgie se démarque par la découverte d'un chapiteau tauriforme.

\section{AUTEURS}

\section{ASTRID NUNN}

Université de Munich 